\title{
The Availability of MeSH in Vendor-Supplied Cataloguing Records, as Seen Through the Catalogue of a Canadian Academic Health Library
}

Pamela S. Morgan

Information Resources Librarian

Health Sciences Library

Memorial University of Newfoundland

\begin{abstract}
This study examines the prevalence of medical subject headings in vendorsupplied cataloguing records for publications contained within aggregated databases or publisher collections. In the first phase, the catalogue of one Canadian academic medical library was examined to determine the extent to which medical subject headings (MeSH) are available in the vendor-supplied records. In the second phase, these results were compared to the catalogues of other Canadian academic medical libraries in order to reach a generalization regarding the availability of $\mathrm{MeSH}$ headings for electronic resources. MeSH was more widespread in records for electronic journals but was noticeably lacking in records for electronic monographs, and for Canadian publications. There is no standard for ensuring $\mathrm{MeSH}$ are assigned to monograph records for health titles and there is no library in Canada with responsibility for ensuring that Canadian health publications receive Medical Subject Headings. It is incumbent upon libraries using $\mathrm{MeSH}$ to ensure that vendors are aware of this need when purchasing record sets.
\end{abstract}

Keywords: Subject headings, full-text databases, MARC records, outsourcing

\section{Introduction}

As electronic resources become more accepted, and expected, in libraries, purchasing of e-journals and of e-books has become a commonplace occurrence. Many libraries now purchase these resources in packages rather than via individual selection. Libraries are then faced with the challenge of making the multitude of individual titles in these packages known to their users. One of the preferred methods is to provide access via the catalogue, whereby every individual title in a package has a MARC record in the library catalogue.

When packages first became available, many libraries tried cataloguing the titles locally and found themselves overburdened by the workload. The packages included such large numbers of titles being acquired at once that it made the timeliness of cataloguing the individual titles a challenge. In addition, in the case 
of aggregated databases of e-journals, the content in the packages was not stable and titles, holdings, or URLs could change at any time. Cataloguing the individual titles in these packages could mean correcting numerous records every month.

For these reasons, the practice of purchasing MARC record sets developed, with libraries purchasing the initial record set at the time of acquisition of a package. Many libraries took the additional step of subscribing to a MARC record service for packages that incur frequent changes and whose records require regular updating.

While it is possible to enhance or customize these purchased records, it is not practical in most cases for the same reason that it is difficult to catalogue and maintain them in the first place. The initial record in the catalogue could be overwritten at any time with a replacement record as titles, editions, coverage, URLs, etc., are modified and require changes to the record.

\section{Background}

Memorial University of Newfoundland has approximately 15,500 undergraduate and 2,500 graduate students on two campuses. As the only university in the province of Newfoundland and Labrador, it offers a wide range of programs at the undergraduate, graduate, and post-graduate level. The university library system, Memorial University Libraries, is a member of the Canadian Research Knowledge Network (CRKN), a consortium of libraries for licensing of electronic resources.

The Health Sciences Library is one of four libraries within the system, and serves the Faculty of Medicine, the School of Nursing, and the School of Pharmacy, a total of approximately 1750 undergraduates, graduates, and faculty. (Table 1)

Table 1: Health Sciences Enrolment

\begin{tabular}{|l|r|r|r|r|}
\hline HEALTH SCIENCES & \multicolumn{1}{|l|}{ Medicine } & \multicolumn{1}{|l|}{ Nursing } & \multicolumn{1}{c|}{ Pharmacy } & \multicolumn{1}{c|}{ Total } \\
\hline Undergraduates & 239 & 952 & 111 & 1302 \\
\hline Graduates & 167 & 83 & 6 & 256 \\
\hline Faculty & 174 & 25 & 10 & 209 \\
\hline Total & 580 & 1060 & 127 & 1767 \\
\hline
\end{tabular}

Memorial's medical school, and therefore the library, is a member of the Association of Faculties of Medicine of Canada (AFMC). The Health Sciences Library is contracted to serve the Health Sciences Centre site of the Health Care Corporation of St. John's, the hospital site at which the university health 
programmes are housed. As well, the library serves as the provincial resource for all health practitioners within the province.

The Health Sciences Library uses the U.S. National Library of Medicine (NLM) classification scheme for all materials except journals, which are shelved by title, and the Medical Subject Headings (MeSH) subject heading scheme for all materials. The three other libraries in the library system use Library of Congress (LC) classification and the Library of Congress Subject Headings (LCSH) subject scheme. The four libraries share the one online catalogue.

In addition to e-journal holdings through full-text aggregator databases, the Health Sciences Library has access to the e-journal packages of most of the major medical journal publishers, as well as to collections of e-books through NetLibrary and Ebrary, through deals within the Memorial University Libraries, and within CRKN. To handle large e-book packages, Memorial has begun purchasing records from the vendor or other record provider. For e-journal packages, Memorial has contracted with Serials Solutions to provide initial records for the packages as well as monthly updates.

As these supplied records became more and more prevalent in the shared catalogue, librarians at the Health Sciences Library began to notice that many health-related titles were not catalogued with Medical Subject Headings (MeSH). There was general discussion within the library as to whether there truly was a problem with MeSH availability and even as to whether this should be a concern, given this age of electronic access and keyword searching. This led to the following questions, which this study addresses:

1. To what extent do purchased records in the health sciences, as seen in Memorial's library catalogue, lack MeSH?

2. Is a lack of MeSH a local problem or are other libraries that use MeSH and purchase records facing the same problem?

\section{Literature Review}

A literature search was conducted to determine if other libraries had identified this as a concern and how they were handling it. No articles were found addressing the issue of MeSH in vendor-supplied MARC records. Only one article dealt with MeSH in purchased or outsourced MARC records and this was a brief comment in the context of outsourcers not being able to handle MESH. (Libby and Caudle). The literature search was expanded to look at several related topics that might indicate whether the library should be concerned if $\mathrm{MeSH}$ is not available:

- The characteristics of MeSH and other subject headings 
- Outsourcing of cataloguing and the purchase of record sets for aggregators

- Keyword searching versus subject searching

\section{Why Use MeSH}

Cataloguing is a cooperative and collaborative endeavour, and requires agreement not only on bibliographic description but also on subject analysis; a term must have the same meaning across catalogues if cooperation in cataloguing is to have any value (Cimino; Gorman; Marshall). Controlled subject headings allow for the consistent definition of terms. This results in increased specificity of the term, providing "greater clarity and reduced ambiguity" (McGregor 339). ). Subject headings also overcome the variability of natural language so that a user does not have to account for synonyms and variations in spelling or terminology (Gault, Schultz, and Davies; McGregor; Shoham and Kedar).

Factors that affect the conduct of a successful search by topic include the subject knowledge of the user, the expression chosen for a search, the subject scheme in use, and how well the chosen search term matches the authorized subject heading (Carlyle). The characteristics of a vocabulary vary with its intended purpose, as different users require different arrangements of concepts. Subject headings manage the difference in popular and technical terms, semantic differences, levels of specificity, context, scope, and coverage (Cimino; Denda; Kreider; Machado; Roe). Therefore many disciplines have their own vocabulary which allows them to meet the needs of their own specific clientele, and which uses the professional terminology of the field. LCSH or other subject heading schemes do not meet the needs for specialized medical terms, and often group similar yet distinct medical concepts into one heading (Olson and Strawn; Smith and Cochrane; Womack).

For example, LCSH uses the popular term AIDS (Disease), whereas MeSH uses the medical term Acquired Immunodeficiency Syndrome. In LCSH, the phrase Risk management represents a broader concept than that same phrase represents in $\mathrm{MeSH}$. MeSH assumes that it is describing concepts from a health point of view so that the term Risk Management automatically refers to risk management in a health setting whereas LCSH, coming from a more general point of view, has to specify Health facilities - Risk management to represent the same concept. In LCSH, Lyme disease is the narrowest term available, whereas in $\mathrm{MeSH}$ it has two narrower terms. MeSH is a specialised language for a special collection and is the accepted vocabulary for medical libraries around the world (Machado; Sievert, Patrick, and Reid; Womack).

In addition, MeSH is the scheme used by the primary article index in medicine, Medline/PubMed, which means that the same term can be used in both the article index and the catalogue. Using MeSH is therefore simpler for users as 
they need only be familiar with the one scheme (Lipscomb; McNutt and Poland; Womack).

Based on this, MeSH would be the optimal subject heading scheme for specialized medical libraries.

\section{Do We Need Subject Access?}

Much has been written in the literature regarding whether keyword searching is adequate or whether a controlled vocabulary is necessary for effective searching. From personal observation serving on the library's Information Desk, few users search via the subject headings. Yet, different people use a wide variety of search terms to describe the same concept (Bates; Murphy et al.). One study reported by Bates estimated that only 10-20\% of users would use the same terminology to represent the same concept (409), while another estimated that $30-50 \%$ of keyword searches of the subject field produce no results (409). Marner (6) studied actual headings and their cross-references to determine whether records could be retrieved and found that while inverted headings matched $84 \%$ of the time, the synonymous terms only matched $10 \%$ of the time.

Gerhan (86) noted that if title is the only means of access, then only $50 \%$ of relevant material in a library catalogue is found, and $48 \%$ of the relevant material required examination of the subject headings in order to determine the relevancy of the material. Subject headings are more likely ( $85 \%$ of the time) to provide effective subject access to materials than title keywords (55\% of the time) (Gerhan 87).

Titles of texts, and even of chapters, are often not usable as they contain words that have no substantive bearing on the subject; "... keywords are only as good as the author makes them. Even after articles, prepositions, and conjunctions are removed from consideration, generic terms like 'report' remain as do metaphors and cute, catchy phrases." (McJunkin 161).

Voorbij (467) reported on a study by Henzler that came to the same conclusion following a study of the Cancernet database, that 35\% of the title words had no equivalent in the thesaurus, $5 \%$ being meaningless words, $25 \%$ being specialized subjects, and 5\% being names or numbers. In two separate studies, both Derry and Dijkers conclude that authors need to provide more useful titles and abstracts to assist researchers in finding relevant articles. Voorbij (473) found that broader searches and narrower searches had differing effectiveness with keyword and subject searching. Using keywords resulted in retrieval of $41 \%$ of the relevant records for broad subjects, while subject headings retrieved $88 \%$ of the relevant records. However, keyword searching was more successful for narrow subjects, resulting in retrieval of $57 \%$ of the relevant records, although still not as successful as subject headings, which remained relatively constant at $86 \%$. 
Enhanced or enriched records make abstracts and tables of contents available for searching in addition to the words in the titles, thus expanding the terms available for keyword searching. Byrum and Williamson (4) reported that enriched records add approximately 15-19 unique subject terms to a record, that table of contents can help in determining relevancy, and that keyword searching of enriched records results in two to three times as many relevant records being retrieved.

However, authors of other studies argue that subject headings are still required, that these enriched records both reduce precision and increase recall, and thus subject headings are needed to determine whether the title retrieved is truly relevant. Keyword searching all too often results in vast amounts of information without context, relevance, or precision (Bates; Carstens and Buchanan; Gorman; Mann; McGregor; Womack; Yee).

Matching of keyword searches to the subject heading field is another area that has been studied. When one searches using keywords, the controlled vocabulary is also searched. McJunkin noted that keyword searching of the subject field can lead to the identification of the appropriate subject term. Carlyle (59) found that keyword searches match an LC subject heading approximately $50 \%$ of the time, and Gross and Taylor (223) estimated that $36 \%$ of the records would not be found if the subject headings were not available. Jenuwine and Floyd reported that while MeSH provides greater specificity than keywords (eliminates irrelevant articles), keywords have greater sensitivity (retrieves a greater number of relevant articles).

Therefore the optimal search is to search keywords in enhanced records that contain subject headings that utilize the terminology most likely to be identified by the user.

\section{What is the Effect of Purchasing MARC Records?}

Problems with the cataloguing of titles in aggregated databases have been identified in the literature. Electronic journal publishing has surpassed the library's ability to keep up with the cataloguing needs (Banush, Kurth, and Pajerak).

A CONSER survey found that $71 \%$ of respondents wanted aggregator titles in their library catalogue and $73 \%$ were willing to buy record sets (Jiang, Baker, and Kresge; Riemer, Wakimoto, and French; Schroeder; Wasylenko; Wakimoto). Another $50 \%$ were willing to assist in the creation of the records (Schroeder). Khurshid (85) estimated that some $90 \%$ of titles in aggregator databases had catalogue copy available for the print version of the journal. The Program for Cooperative Cataloging (PCC) Task Force on Journals in Aggregator Databases examined the situation (Jiang, Baker, and Kresge; Martin and Saxton; Riemer, 
Wakimoto, and French) and recommended the creation of machine-derived records from the print record, human creation being deemed too heavy a workload. EBSCO Information Services (http://www.ebsco.com), which supplies many aggregated databases, subsequently successfully tested the creation and loading of records for titles in aggregated databases derived from the print record. However, the loading of such record sets creates its own problems.

In a continuation of the debate regarding records for microforms, there was disagreement regarding how many records per title should be in the library catalogue. Many libraries argue that there should be one record per title, with all holdings and access points available through the one record. In this Single Record concept, there is one record for a title with all holdings attached to this one record, regardless of the format or of multiple instances of URLS. It is userfriendly as there is only one hit for a particular title, with all available information in the one place. Other libraries argue that there should be a separate record for every instance of the title. In this Multiple Record concept, there is a separate record for each different holding of a particular title; every format of the one title has its own record, as does every different electronic access point. While this version is easier for manipulation by computers, it is not user-friendly as there are multiple records for the one piece of intellectual content in which the user is interested (Bland). The EBSCO test demonstrated that single records created additional work for cataloguing departments trying to merge the various holdings into one and that multiple records would be more efficient as the vendor can simply replace the record whenever a change is needed, without affecting any other holdings in the catalogue (Reimer, Wakimoto, \& French).

Purchasing records relieves pressure on cataloguing departments when acquiring large collections (Banerjee), enabling records to get into the library catalogue faster, as turnaround time is typically reduced and backlogs are eliminated or reduced. Catalogue maintenance is reduced as records can be automatically replaced with updated records. The purchase of records can also allow the handling of specialized materials where local expertise is lacking.

Problems associated with the purchase of catalogue records include a lack of control, and some loss of quality, in addition to technical issues. There is a limited ability to customize the records and because the records are rarely "permanent", they cannot readily be enhanced or modified in-house (Khurshid; Leathem; Martin and Saxton). While the biggest concern regarding vendor records had been quality, vendors are now providing most of the serial MARC records for their collections through copy cataloguing, using CONSER and other standardized records whenever possible (Young; Brisson). Behesti, Large, and Riva reported on Canadian libraries using Library and Archives Canada as a source for cataloguing copy, and state that approximately 30,000 records are created annually (45). They also estimate that Canadian universities use Library and Archives Canada copy for $14 \%$ of their titles (49). 


\section{Part I - Availability of MeSH in Memorial University's library catalogue}

In this part, Memorial University of Newfoundland's library catalogue is examined to determine the extent to which medical subject headings (MeSH) are available in the vendor-supplied records.

\section{Methodology}

As previously mentioned, observations by Health Sciences librarians raised a concern as to the prevalence of MeSH in Memorial University Libraries' purchased records. The librarians further felt that the percentage of titles with $\mathrm{MeSH}$ was considerably lower for Canadian titles than for American or international titles. The catalogue of the Memorial University Libraries was examined to determine the percentage of records without MeSH. In order to identify only materials of interest to the primary users of the Health Sciences Library, which could reasonably be expected to have $\mathrm{MeSH}$, the following subject-based searches were conducted:

a) MEDICINE search string: medicine or physician or physicians or doctor or doctors

b) NURSING search string: nursing or nurse or nurses

c) PHARMACY search string: pharmacy or pharmacist or pharmacists or pharmacology or drug or drugs

d) HEALTH search string: health

The searches were broken down into these subject areas in order to make the results manageable and so as to not trigger a system error with too large a result. It also allows for comparison among the various health fields.

The searches were further broken down by record sets, which allowed the search to be limited to supplied catalogue records. The Memorial University Libraries use Sirsi's Unicorn system for cataloguing, and a code indicating the record set is inserted in each record when the supplied record sets are uploaded. This allows for ready identification of those purchased sets. Thus each of the above searches was conducted applying a record set limit for Serials Solutions, Ebrary, and Ebrary Canada, which consists of the Canadian Publishers Collection, the Canadian Public Policy Collection, and the Canadian Health Research Collection from the Canadian Electronic Library (http://www.gibsonlibraryconnections.ca/glc cel.htm). An additional search was done adding the term "memorialhealth" to the search string in order to isolate those Ebrary Canada records that are specifically part of the Canadian Health Research Collection, which, as a health collection, could be expected to have a high percentage of MeSH. 
In addition, NetLibrary records were examined. NetLibrary was the first ebook set acquired by the Memorial University Libraries main branch, the Queen Elizabeth II Library, and titles in this collection were catalogued individually following their usual procedure of searching for acceptable copy and doing original cataloguing if acceptable copy was not found. Because NetLibrary was purchased by the Queen Elizabeth II Library, they were not concerned with the presence of MeSH in the records. If MeSH existed, it was retained, but it was not added unless specifically requested by the Health Sciences Library on a title by title basis. Because it was catalogued locally, NetLibrary was not established as a set within Unicorn. To retrieve the NetLibrary records, "AND NetLibrary" was added to the subject search string.

In total, 20 searches were conducted using the "List Bibliography" report of Unicorn. The records were then analyzed utilizing the following process:

1) Eliminated those that were out of scope (mainly pertinent for the search string "Health").

2) Counted the records that had MeSH.

3) Saved the records without MeSH to a separate "No Mesh" file.

4) Scanned the "No Mesh" file to determine the breakdown of subject headings that were available, and counted the records.

5) Identified those records in the original file that contained the truncated word Canad* in the record, while recognizing that this would miss those that were specific to a province. Saved those to a separate "Canada" file. This was not done for the Ebrary Canada or the MemorialHealth files, as these are all Canadian titles by definition.

6) Scanned the "Canada" file, as well as Ebrary Canada and MemorialHealth, to determine the number of Canadian titles with MeSH and those which were created by Library and Archives Canada or by the Canada Institute for Scientific and Technical Information (CISTI).

It should be noted that there was no attempt to verify the accuracy of the headings or of the coding of the headings. The records and field labels were accepted as presented in the catalogue.

\section{Analysis}

\section{Journals}

The percentage of journal records with $\mathrm{MeSH}$, as obtained from Serials Solutions (Table 2), ranged from a high of $86.98 \%$ for Health to a low of $79.94 \%$ for Pharmacy. Overall, $84.37 \%$ of the Serials Solutions records examined contained $\mathrm{MeSH}$, and 2.1\% had either no subject heading or a generic subject heading.

Of Canadian titles in Serials Solutions, $73.68 \%$ overall contained $\mathrm{MeSH}$, and $48.68 \%$ of the records were created by Library and Archives Canada or CISTI. 
However, in the case of Canadian titles, there was a much wider discrepancy between the highest and lowest, with $90.91 \%$ of Nursing titles containing MeSH and only $40 \%$ of Pharmacy titles. Only $68.42 \%$ of the Medicine titles contained $\mathrm{MeSH}$.

Table 2: Journals with MeSH

\begin{tabular}{|l|c|c|c|c|c|}
\hline Journals (Serials Solutions) & MEDICINE & NURSING & PHARMACY HEALTH & TOTAL \\
\hline Total Records & 1020 & 528 & 349 & 1429 & 3326 \\
\hline Total Records with MeSH & $\begin{array}{c}834 \\
(81.76 \%)\end{array}$ & $\begin{array}{c}450 \\
(85.23 \%)\end{array}$ & $\begin{array}{c}279 \\
(79.94 \%)\end{array}$ & $\begin{array}{c}1243 \\
(86.98 \%)\end{array}$ & $\begin{array}{c}2806 \\
(84.37 \%)\end{array}$ \\
\hline Canadian Subset & 19 & 11 & 5 & 41 & 76 \\
\hline Total Canadian Titles & $\begin{array}{c}13 \\
(68.42 \%)\end{array}$ & $\begin{array}{c}10 \\
(90.91 \%)\end{array}$ & $\begin{array}{c}2 \\
(40.00 \%)\end{array}$ & $\begin{array}{c}31 \\
(75.61 \%)\end{array}$ & $\begin{array}{c}56 \\
(73.68 \%)\end{array}$ \\
\hline Total Records with MeSH & & & & & \\
\hline Cataloguing Source & 9 & $\begin{array}{c}3 \\
(27.27 \%)\end{array}$ & $\begin{array}{c}13 \\
(260.00 \%)\end{array}$ & $\begin{array}{c}12 \\
(29.27 \%)\end{array}$ & $\begin{array}{c}37 \\
(48.68 \%)\end{array}$ \\
\hline Total Records Created by LAC/CISTI & $(47.37 \%$ & &
\end{tabular}

\section{Monographs: Ebrary}

The percentage of examined records with MeSH in Ebrary's Academic Complete package (Table 3 ) ranged from a high of $4.83 \%$ for Medicine to a low of $3.06 \%$ for Health. Overall, less than $4 \%$ of the Ebrary records in the health sciences contained MeSH, while all records contained LCSH.

Of Canadian titles in Ebrary, $50 \%$ contained $\mathrm{MeSH}$, however this is only six titles over two subject areas (Medicine and Pharmacy). It is not possible to tell who created the records since the only code listed in the Cataloguing Source (MARC Tag 040) field is that of Ebrary itself.

Table 3: Ebrary Records with MeSH

\begin{tabular}{|l|c|c|c|c|c|}
\hline Ebrary & MEDICINE & NURSING & PHARMACY & HEALTH & TOTAL \\
\hline Total Records & 663 & 63 & 234 & 1211 & 2171 \\
\hline Total Records with MeSH & $\begin{array}{c}32 \\
(4.83 \%)\end{array}$ & $\begin{array}{c}03 \\
(4.76 \%)\end{array}$ & $\begin{array}{c}9 \\
(3.85 \%)\end{array}$ & $\begin{array}{c}37 \\
(3.06 \%)\end{array}$ & $\begin{array}{c}81 \\
(3.73 \%)\end{array}$ \\
\hline Canadian Subset & & & & & \\
\hline Total Canadian Titles & 3 & 0 & 1 & 8 & 12 \\
\hline Total Records with MeSH & $\begin{array}{c}2 \\
(66.67 \%)\end{array}$ & $\begin{array}{c}0 \\
(0.00 \%)\end{array}$ & $\begin{array}{c}0 \\
(0.00 \%)\end{array}$ & $\begin{array}{c}5 \\
(50.00 \%)\end{array}$ & $\begin{array}{c}6 \\
(50.00 \%)\end{array}$ \\
\hline
\end{tabular}




\section{Mongraphs: Ebrary Canada}

Less than 1\% (11 of 1777) of the records in the Ebrary Canada collection contained MeSH (Table 4), ranging from a high of $1.43 \%$ for Nursing to a low of $0 \%$ for Pharmacy. Only one record did not contain LCSH. Thirteen percent of the records were created by Library and Archives Canada or CISTI.

Table 4: Ebrary Canada Collection Records with MeSH

\begin{tabular}{|l|c|c|c|c|c|}
\hline Ebrary Canada & MEDICINE & NURSING & PHARMACY & HEALTH & TOTAL \\
\hline Total Records & 171 & 140 & 132 & 1334 & 1777 \\
\hline Total Records with MeSH & $\begin{array}{c}1 \\
(0.58 \%)\end{array}$ & $\begin{array}{c}2 \\
(1.43 \%)\end{array}$ & $\begin{array}{c}0 \\
(0.00 \%)\end{array}$ & $\begin{array}{c}8 \\
(0.60 \%)\end{array}$ & $\begin{array}{c}11 \\
(0.62 \%)\end{array}$ \\
\hline Cataloguing Source & & & & & \\
\hline Total Records Created by LAC/CISTI & $\begin{array}{c}41 \\
(23.98 \%)\end{array}$ & $\begin{array}{c}0 \\
(0.00 \%)\end{array}$ & $\begin{array}{c}16 \\
(12.12 \%)\end{array}$ & $\begin{array}{c}177 \\
(13.27 \%)\end{array}$ & $\begin{array}{c}234 \\
(13.17 \%)\end{array}$ \\
\hline
\end{tabular}

\section{Mongraphs: Canadian Health Research Collection (MemorialHealth Subset)}

Only two records out of the 1,064 records examined in the Canadian Health Research Collection (Table 5) contained MeSH. $10.62 \%$ of the records were created by either Library and Archives Canada or CISTI.

Table 5: Canadian Health Research Collection Records with MeSH

\begin{tabular}{|l|c|c|c|c|c|}
\hline MemorialHealth & MEDICINE & NURSING & PHARMACY & HEALTH & TOTAL \\
\hline Total Records & 82 & 95 & 74 & 813 & 1064 \\
\hline Total Records with MeSH & $\begin{array}{c}1 \\
(1.22 \%)\end{array}$ & $\begin{array}{c}0 \\
(0.00 \%)\end{array}$ & $\begin{array}{c}0 \\
(0.00 \%)\end{array}$ & $\begin{array}{c}1 \\
(0.12 \%)\end{array}$ & $\begin{array}{c}2 \\
(0.19 \%)\end{array}$ \\
\hline Cataloguing Source & & & & & \\
\hline Total Records Created by LAC/CISTI & $(10.98 \%))$ & $(3.16 \%)$ & $\begin{array}{c}8 \\
(10.81 \%)\end{array}$ & $\begin{array}{c}93 \\
(11.44 \%)\end{array}$ & $\begin{array}{c}113 \\
(10.62 \%)\end{array}$ \\
\hline
\end{tabular}

\section{Total Monographs}

Because MemorialHealth is a subset of Ebrary Canada, these records are excluded from the overall totals for monographs (Table 6).

Overall, only $2.33 \%$ of the monograph records contained $\mathrm{MeSH}$, while only one record $(.03 \%)$ did not contain LCSH. The subject area with the highest percentage of $\mathrm{MeSH}$ in the records was medicine, and this was less than $4 \%$.

Of the total monograph purchased records identified as Canadian, overall, less than $1 \%$ (17 of 1789 records) contained MeSH. $13.08 \%$ of the records were created by either Library and Archives Canada or CISTI. 
Table 6: Total Monographs with MeSH

\begin{tabular}{|c|c|c|c|c|c|}
\hline TOTAL MONOGRAPHS & MEDICINE & NURSING & PHARMACY & HEALTH & TOTAL \\
\hline Total Records & 834 & 203 & 366 & 2545 & 3948 \\
\hline Percentage with MeSH & $\begin{array}{c}33 \\
(3.96 \%) \\
\end{array}$ & $\begin{array}{c}5 \\
(2.46 \%) \\
\end{array}$ & $\begin{array}{c}9 \\
(2.46 \%) \\
\end{array}$ & $\begin{array}{c}45 \\
(1.77 \%) \\
\end{array}$ & $\begin{array}{c}92 \\
(2.33 \%) \\
\end{array}$ \\
\hline \multicolumn{6}{|l|}{ Canadian Subset } \\
\hline Total Canadian Titles & 174 & 140 & 133 & 1342 & 1789 \\
\hline Total Records with MeSH & $\begin{array}{c}3 \\
(1.72 \%) \\
\end{array}$ & $\begin{array}{c}2 \\
(1.43 \%) \\
\end{array}$ & $\begin{array}{c}0 \\
(0.00 \%)\end{array}$ & $\begin{array}{c}12 \\
(0.89 \%) \\
\end{array}$ & $\begin{array}{c}17 \\
(0.95 \%) \\
\end{array}$ \\
\hline \multicolumn{6}{|l|}{ Cataloguing Source } \\
\hline Total Records Created by LAC/CISTI & $\begin{array}{c}41 \\
(23.56 \%)\end{array}$ & $\begin{array}{c}0 \\
(0.00 \%)\end{array}$ & $\begin{array}{c}16 \\
(12.03 \%)\end{array}$ & $\begin{array}{c}177 \\
(13.19 \%)\end{array}$ & $\begin{array}{c}234 \\
(13.08 \%)\end{array}$ \\
\hline
\end{tabular}

\section{NetLibrary Comparison}

The percentage of NetLibrary records with MeSH (Table 7), ranged from a high of $91.84 \%$ for Nursing to a low of $40 \%$ for Pharmacy. Overall, $72.33 \%$ of NetLibrary records in the health sciences contained MeSH. Because they are locally catalogued records rather than purchased records, all have at least an LC subject heading.

Of Canadian titles in NetLibrary, $50 \%$ containeded MeSH. However, this is only two of four Health titles. None of the other subject areas contained MeSH. None of the records were created by Library and Archives Canada or CISTI.

The high percentage of Nursing records with MeSH can be explained because the librarian with subject responsibility for Nursing reviewed all NetLibrary titles received in the initial package and requested that MeSH be added to those relevant to nursing students. When Nursing's $91 \%$ figure is excluded from the calculation of the total, $63.64 \%$ of the examined NetLibrary books contained $\mathrm{MeSH}$. This figure is a more accurate percentage for the number of records within NetLibrary that have MeSH as part of the supplied record since it excludes the records for which MeSH was specifically added versus the records that had $\mathrm{MeSH}$ as part of the record obtained via copy cataloguing. 
Table 7: NetLibrary Monographs

\begin{tabular}{|c|c|c|c|c|c|}
\hline Netlibrary & MEDICINE & NURSING & PHARMACY & HEALTH & TOTAL \\
\hline Total Records & 45 & 49 & 10 & 55 & 159 \\
\hline Total Records with MeSH & $\begin{array}{c}30 \\
(66.67 \%) \\
\end{array}$ & $\begin{array}{c}45 \\
(91.84 \%) \\
\end{array}$ & $\begin{array}{c}4 \\
(40.00 \%) \\
\end{array}$ & $\begin{array}{c}36 \\
(65.45 \%) \\
\end{array}$ & $\begin{array}{c}115 \\
\star \star *(72.33 \%) \\
\end{array}$ \\
\hline \multicolumn{6}{|l|}{ Canadian Subset } \\
\hline Total Canadian Titles & 0 & 0 & 0 & 4 & 4 \\
\hline Total Records with MeSH & $\begin{array}{c}0 \\
(0.00 \%) \\
\end{array}$ & $\begin{array}{c}0 \\
(0.00 \%) \\
\end{array}$ & $\begin{array}{c}0 \\
(0.00 \%) \\
\end{array}$ & $\begin{array}{c}2 \\
(50.00 \%) \\
\end{array}$ & $\begin{array}{c}2 \\
(50.00 \%) \\
\end{array}$ \\
\hline \multicolumn{6}{|l|}{ Cataloguing Source } \\
\hline Total Records Created by LAC/CISTI & $\begin{array}{c}0 \\
(0.00 \%) \\
\end{array}$ & $\begin{array}{c}0 \\
(0.00 \%) \\
\end{array}$ & $\begin{array}{c}0 \\
(0.00 \%) \\
\end{array}$ & $\begin{array}{c}0 \\
(0.00 \%) \\
\end{array}$ & $\begin{array}{c}0 \\
(0.00 \%) \\
\end{array}$ \\
\hline
\end{tabular}

** Percentage when Nursing is excluded is $63.64 \%$

\section{Overall Journals and Monographs}

The percentage of purchased monograph and journal records with MeSH (Table 8) ranged from a high of $62.24 \%$ for Nursing to a low of $32.41 \%$ for Health. Overall, only $40 \%$ of purchased records in the health sciences contained $\mathrm{MeSH}$, and only $1 \%$ had either no subject heading or a generic subject heading.

Less than $4 \%$ of the overall Canadian titles contained MeSH. $14.53 \%$ of the records were created by either Library and Archives Canada or CISTI. However, in the case of Canadian titles, there was less discrepancy between the highest and lowest, with $8.29 \%$ of Medicine titles containing MeSH and $1.45 \%$ of Pharmacy titles.

Table 8: Overall Total Purchased Records with MeSH

\begin{tabular}{|l|c|c|c|c|c|}
\hline TOTAL & MEDICINE & NURSING & PHARMACY & HEALTH & TOTAL \\
\hline Total Records & 1854 & 731 & 715 & 3974 & 7274 \\
\hline Total Records with MeSH & $\begin{array}{c}867 \\
(46.76 \%)\end{array}$ & $\begin{array}{c}455 \\
(62.24 \%)\end{array}$ & $\begin{array}{c}288 \\
(40.28 \%)\end{array}$ & $\begin{array}{c}1288 \\
(32.41 \%)\end{array}$ & $\begin{array}{c}2898 \\
(39.84 \%)\end{array}$ \\
\hline Canadian Subset & & & & & \\
\hline Total Canadian Titles & 193 & 151 & 138 & 1383 & 1865 \\
\hline Total Records with MeSH & $\begin{array}{c}16 \\
(8.29 \%)\end{array}$ & $\begin{array}{c}12 \\
(7.95 \%)\end{array}$ & $\begin{array}{c}2 \\
(1.45 \%)\end{array}$ & $\begin{array}{c}43 \\
(3.11 \%)\end{array}$ & $\begin{array}{c}73 \\
(3.91 \%)\end{array}$ \\
\hline Cataloguing Source & & & & & 13 \\
\hline Total Records Created by LAC/CISTI & $\begin{array}{c}50 \\
(25.91 \%)\end{array}$ & $\begin{array}{c}3 \\
(1.99 \%)\end{array}$ & $\begin{array}{c}29 \\
(21.01 \%)\end{array}$ & $\begin{array}{c}189 \\
(13.67 \%)\end{array}$ & $\begin{array}{c}271 \\
(14.53 \%)\end{array}$ \\
\hline
\end{tabular}




\section{Discussion}

The low number of monograph records with MeSH decreases the overall averages for all subject areas. While the total number of records with $\mathrm{MeSH}$ is greater for Medicine, Nursing contains a higher percentage of MeSH than any other subject area, for both journals and monographs. The $80 \%$ or higher number for journals in all subject areas (Table 9) would indicate that CONSER has done a good job in trying to make quality journal records with all relevant subject headings available for journal aggregators and vendors. This is in contrast to the low numbers for monographs with $\mathrm{MeSH}$, which may indicate that many vendors are following the Program for Cooperative Cataloguing (PCC) guidelines that LCSH is the only subject heading that they need apply. This can be further seen when contrasting NetLibrary's 64\% overall records containing MeSH (Table 7) with the other general collection of e-books, Ebrary (Table 3), which has only $4 \%$ of its records containing MeSH. In the case of NetLibrary, the records are copy catalogue records while in the case of Ebrary, the cataloguing source is listed as Ebrary itself.

It is assumed that all records were accurate as to the use of the Cataloguing Source field (Marc Tag 040) in the MARC records. No attempt was made to compare the records in the library catalogues with records in online cataloguing sources such as OCLC to verify that the libraries had not modified the records locally.

It seems that this deficiency of MeSH in purchased records could be alleviated if the existing full-level copy contained $\mathrm{MeSH}$ and was utilized by vendors. The deficiency is particularly obvious for Canadian titles (Table 9). With the exception of Nursing journals, the numbers of Canadian titles with MeSH notably decrease as compared with the overall totals.

Table 9: Comparison of Subject Areas with MeSH , All and Canadian

\begin{tabular}{|l|l|l|l|}
\hline & Type & All & Canadian \\
\hline Health & Journals & $86.98 \%$ & $75.61 \%$ \\
\hline Nursing & Journals & $85.23 \%$ & $90.91 \%$ \\
\hline Medicine & Journals & $81.76 \%$ & $68.42 \%$ \\
\hline Pharmacy & Journals & $79.94 \%$ & $40.00 \%$ \\
\hline Medicine & Monographs & $3.96 \%$ & $1.72 \%$ \\
\hline Nursing & Monographs & $2.46 \%$ & $1.43 \%$ \\
\hline Pharmacy & Monographs & $2.46 \%$ & $0.00 \%$ \\
\hline Health & Monographs & $1.77 \%$ & $0.89 \%$ \\
\hline Nursing & Overall & $62.24 \%$ & $7.95 \%$ \\
\hline Medicine & Overall & $46.76 \%$ & $8.29 \%$ \\
\hline Pharmacy & Overall & $40.28 \%$ & $1.45 \%$ \\
\hline Health & Overall & $37.41 \%$ & $3.11 \%$ \\
\hline
\end{tabular}


As was seen in Table 2, only $74 \%$ of the journals identified as Canadian contained $\mathrm{MeSH}$, compared to $84 \%$ of the overall journal collection. However 37 Canadian titles (49\%) were created by Library and Archives Canada or CISTI, according to MARC tag 040. From this discrepancy, it can be established that other libraries are creating the MeSH copy for these titles. And as seen in Table 6 , less than $1 \%$ of the Canadian monographs contain $\mathrm{MeSH}$, yet $13 \%$ are created by either Library and Archives Canada or CISTI. So it is demonstrated that neither Library and Archives Canada nor CISTI are adding MeSH to their original records.

The websites of the four major libraries in Canada and the United States were examined to determine their cataloguing policies with respect to subject headings. The four libraries were chosen for their status as "national" libraries, which imply a level of standard, and for the role they play in developing cataloguing policies and providing Cataloguing In Publication data (CIP).

- Library and Archives Canada, the national library of Canada, developer of Canadian Subject Headings, and provider of CIP for Canadian publications <http://www.collectionscanada.ca/>

- Canada Institute for Scientific and Technical Information (CISTI), the library of the National Research Council of Canada, which acts as a national science library and is the lead coordinator for Canadian health libraries in dealings with the National Library of Medicine < http://cistiicist.nrc-cnrc.gc.ca/main e.html>

- National Library of Medicine, a part of the National Institutes of Health, the developing library of NLM classification and Medical Subject Headings, and a contributor to CIP for American publications $<$ http://www.nlm.nih.gov/>

- Library of Congress, which acts as the national library of the United States, developer of the LC classification and LC Subject Headings, main provider of CIP for American publications, and one of the leading players in developing cataloguing policy for North American libraries $<$ http://www.loc.gov/>

As can be seen from Table 10, only the National Library of Medicine actually uses MeSH as a subject heading scheme. As a specialized subject heading, $\mathrm{MeSH}$ is not considered a priority for the cataloguing resources of the Canadian national libraries (Bill Leonard, Information Standards Specialist, Library and Archives Canada. Personal communication. October 15, 2007; Jonathan Makepeace, Manager, Serials, CISTI. Personal communication. October 15, 2007). Thus there is no "national" library in Canada providing MeSH cataloguing copy for the medical libraries within Canada or for Canadian health publications. Copy with MeSH can only be obtained for Canadian publications if a Canadian medical library provides original cataloguing, or if an American library acquires and catalogues the item. 
Table 10: Cataloguing Policies of National Libraries

\begin{tabular}{|l|l|}
\hline LIBRARY & SUBJECT HEADING SCHEME USED \\
\hline Library and Archives & - indicates it follows LC policies as much as possible \\
Canada & - LCSH for English subject headings \\
& - RVM for French subject headings \\
& - Canadian Subject Headings for English headings \\
& requiring special Canadian treatment \\
\hline CISTI & - no policy specified online \\
& - library catalogue uses LCSH \\
\hline Library of Congress & - LCSH \\
\hline National Library of Medicine & - MeSH \\
& - LCSH for peripheral materials \\
\hline
\end{tabular}

The Program for Cooperative Cataloguing (PCC) is an international cooperative aimed at enabling timely and cost-effective cataloguing that meets accepted standards. Among its sections are NACO (name authorities), SACO (subject authorities), and CONSER (serials records). CONSER provides a source of high quality bibliographic records, primarily through the OCLC database and MARC services of the Library of Congress and Library and Archives Canada. It was a PCC CONSER Task Force that began examining analytic records for aggregated databases and developed recommendations. It was also the PCC that developed MARC Record Guidelines for Monograph Aggregator Vendors, which specified that LCSH should be used for monographs. There does not appear to be a similar specification of subject heading scheme for serials.

There are several levels of PCC membership available. In Canada, only the Library and Archives Canada is a full member. "Enhance" status is available to libraries that wish to work on particular projects to enrich existing records by adding particular details. One example of a project would be adding MeSH to existing records.

Following this study, an additional study was conducted to determine how other Canadian medical libraries were handling $\mathrm{MeSH}$, or the lack thereof, in their catalogues. 


\section{Part 2 - Comparison with Other Canadian Medical Library Catalogues}

In this part, the previous results which were relevant only to Memorial University of Newfoundland are compared to the catalogues of other Canadian academic medical libraries in order to reach a generalization regarding the availability of $\mathrm{MeSH}$ headings on vendor-supplied records for electronic resources. This was done in two steps, first by determining the prevalence of MeSH in Canadian academic medical libraries, and secondly, for those libraries which use MeSH, by examining their records for standard works to determine the source of records containing MeSH.

\section{Methodology}

The Association of Faculties of Medicine of Canada (AFMC) consists of the seventeen faculties of medicine in Canada. The library catalogues for each of the libraries supporting these faculties were checked to determine the prevalence of Medical Subject Headings (MeSH). Since all the catalogues are publicly available, searching the catalogue as opposed to conducting a survey guaranteed that $100 \%$ of the libraries would be represented in the study. Searches were conducted for selected texts and journals that every medical library could be expected to hold (Table 11) and the MARC record was examined, where possible. Only the French language library catalogues did not have an option for viewing the MARC record.

Table 11: Selection of Journals and Monographs

\begin{tabular}{|l|l|}
\hline \multicolumn{1}{|c|}{ Journals } & \multicolumn{1}{c|}{ Monographs } \\
\hline BMJ & Harrison's Principles of Internal Medicine \\
\hline Canadian Family Physician & Hurst's The Heart \\
\hline CMAJ & Rudolph's Pediatrics \\
\hline JAMA & Smith's General Urology \\
\hline New England Journal of Medicine & Williams Obstetrics \\
\hline
\end{tabular}

The Canadian Research Knowledge Network (CRKN) is a partnership of Canadian universities aimed at licensing electronic resources on a national basis. Individual universities can choose whether or not to opt into the various packages that are negotiated. All AFMC universities are members of the CRKN. On the assumption that each library system which has an AFMC library would have chosen to participate in the CRKN license for the major journal publishers, the cataloguing records of those libraries that use MeSH were further examined to determine 1) if these libraries purchase copy or catalogue package titles locally, and 2) whether $\mathrm{MeSH}$ is available for the package titles. 
Memorial University of Newfoundland's library catalogue was used to identify a selection of package titles. An attempt was made to choose more specialised titles that would probably not be acquired on an individual basis by most medical libraries. This would allow a judgement as to whether the libraries had picked up a package. A total of sixteen titles were chosen, representing the publishers Springer, Elsevier, Sage, Blackwell, and Wiley. Mixes of titles both with and without MeSH were included.

These sixteen titles were searched in the public catalogues of the other nine AFMC libraries that use MeSH (Memorial already serving as the baseline) to determine whether MeSH was used in these package titles. In cases where a library had more than one record for a title, the record pointing to the relevant electronic version was examined. Since it is known that Memorial buys its cataloguing records for package titles and does not edit them, it was believed that this could be used as a baseline to find out whether other libraries were obtaining MeSH for these titles or editing records to add MeSH.

\section{Analysis}

Of the seventeen faculties of medicine in Canada (Table 12), fifteen have health libraries within the university. The remaining two, Toronto and Western Ontario, include health sciences within a larger science library. Of the seventeen, ten (58.8\%) use MeSH for both monographs and serials, four (23.5\%) use LCSH, and the three (17.7\%) French-language faculties based in the province of Québec use French subject headings. While it could have been expected that the two health libraries that are included within a larger library would not use the specialized medical subject headings, this was not correct as only one uses LCSH while the other does use MeSH.

Table 12: Medical Libraries and Subject Schemes

\begin{tabular}{|c|c|c|c|c|}
\hline Faculty of Medicine & $\begin{array}{l}\text { Medical / } \\
\text { Health } \\
\text { Library }\end{array}$ & Library Website & $\begin{array}{l}\text { Subject } \\
\text { Scheme }\end{array}$ & $\begin{array}{l}3 \text { letter } \\
\text { code }\end{array}$ \\
\hline Université de Montréal & YES & http://www.bib.umontreal.ca/SA/ & French & \\
\hline Université de Sherbrooke & YES & $\begin{array}{l}\text { http://www.usherbrooke.ca/jeveux/c } \\
\text { ampus/c sante.html }\end{array}$ & French & \\
\hline Université Laval & YES & $\begin{array}{l}\text { http://www.bibl.ulaval.ca/mieux/utilis } \\
\text { er/localisations/bs }\end{array}$ & French & \\
\hline University of Alberta & YES & $\begin{array}{l}\text { http://www.library.ualberta.ca/about } \\
\text { us/health/index.cfm }\end{array}$ & $\mathrm{LCSH}$ & \\
\hline University of Ottawa & YES & $\begin{array}{l}\text { http://www.biblio.uottawa.ca/health/i } \\
\text { ndex-e.php }\end{array}$ & $\mathrm{LCSH}$ & \\
\hline University of Saskatchewan & YES & https://library.usask.ca/hsl & $\mathrm{LCSH}$ & \\
\hline University of Toronto & Partial & http://www.library.utoronto.ca/gerste & $\mathrm{LCSH}$ & \\
\hline
\end{tabular}




\begin{tabular}{|c|c|c|c|c|}
\hline & (Science) & in/ & & \\
\hline Dalhousie University & YES & $\begin{array}{l}\text { http://www.library.dal.ca/newsite/Loc } \\
\text { ations/Kellogg\%20- } \\
\% 20 \text { Health\%20Sciences/ }\end{array}$ & $\mathrm{MeSH}$ & DAL \\
\hline $\begin{array}{l}\text { Laurentian University \& } \\
\text { Lakehead University }\end{array}$ & YES & $\begin{array}{l}\text { http://www.normed.ca/library/index.h } \\
\mathrm{tm}\end{array}$ & $\mathrm{MeSH}$ & LAL \\
\hline McGill University & YES & http://www.health.library.mcgill.cal & $\mathrm{MeSH}$ & MCG \\
\hline McMaster University & YES & http://hsl.mcmaster.cal & $\mathrm{MeSH}$ & $\mathrm{MCM}$ \\
\hline $\begin{array}{l}\text { Memorial University of } \\
\text { Newfoundland }\end{array}$ & YES & http://www.library.mun.ca/hsl/ & $\mathrm{MeSH}$ & MUN \\
\hline $\begin{array}{l}\text { Queen's University at } \\
\text { Kingston }\end{array}$ & YES & http://library.queensu.ca/webmed/ & $\mathrm{MeSH}$ & QUE \\
\hline $\begin{array}{l}\text { University of British } \\
\text { Columbia }\end{array}$ & YES & http://www.library.ubc.ca/life/ & $\mathrm{MeSH}$ & UBC \\
\hline University of Calgary & YES & $\begin{array}{l}\text { http://library.ucalgary.ca/branches/h } \\
\text { ealthscienceslibrary/ }\end{array}$ & $\mathrm{MeSH}$ & CAL \\
\hline University of Manitoba & YES & $\begin{array}{l}\text { http://umanitoba.ca/libraries/units/he } \\
\text { alth/ }\end{array}$ & $\mathrm{MeSH}$ & MAN \\
\hline $\begin{array}{l}\text { University of Western } \\
\text { Ontario }\end{array}$ & \begin{tabular}{|l} 
Partial \\
(Science \& \\
Engineering
\end{tabular} & http://www.lib.uwo.ca/taylor/ & $\mathrm{MeSH}$ & UWO \\
\hline
\end{tabular}

The results from the analysis of $\mathrm{MeSH}$ as applied to specific titles were inconclusive (Table 13). Since the majority of the titles searched were not available in the UBC catalogue, it can be concluded that either UBC does not participate in most of the packages or it does not add cataloguing records for the package titles to its catalogue.

Table 13: Occurrence of MeSH in Library Catalogues

\begin{tabular}{|l|l|l|l|l|l|l|l|l|l|l|}
\hline TITLE & MUN & DAL & CAL & LAL & MAN & MCG & MCM & QUE & UBC & UWO \\
\hline Acta tropica & NO & YES & YES & YES & YES & YES & YES & YES & NO & NO \\
\hline Advances in space research & YES & YES & NO & NO & NO & NO & NO & NO & NO & NO \\
\hline American journal of industrial medicine & NO & YES & YES & NO & YES & YES & YES & YES & YES & YES \\
\hline Diabetic medicine & NO & YES & YES & YES & YES & YES & YES & YES & YES & YES \\
\hline Gynaekologe & NO & YES & YES & NO & YES & YES & YES & YES & YES & NO \\
\hline Home health care management \& practice & YES & YES & YES & NO & YES & YES & YES & YES & NA & YES \\
\hline Journal of health psychology & NO & YES & YES & NO & YES & YES & YES & YES & NA & NO \\
\hline Journal of intellectual disabilities & NO & YES & YES & YES & YES & YES & YES & YES & NA & NO \\
\hline Journal of medical ultrasonics & YES & YES & YES & YES & YES & YES & YES & YES & NA & NO \\
\hline $\begin{array}{l}\text { Journal of trace elements in experimental } \\
\text { medicine }\end{array}$ & YES & NO & YES & NO & YES & YES & YES & YES & NA & NO \\
\hline Magma & NO & YES & YES & YES & YES & YES & YES & YES & NA & NO \\
\hline
\end{tabular}




\begin{tabular}{|l|l|l|l|l|l|l|l|l|l|l|}
\hline Seminars in integrative medicine & NO & YES & YES & YES & NO & YES & YES & YES & NO & NO \\
\hline Sleep and breathing & NO & NA & YES & NO & YES & YES & YES & YES & NA & NO \\
\hline $\begin{array}{l}\text { The international journal of medical } \\
\text { robotics + computer assisted surgery }\end{array}$ & NO & YES & NA & NO & YES & YES & YES & YES & NA & YES \\
\hline Transfusion medicine & NO & YES & YES & YES & YES & YES & YES & YES & NA & NO \\
\hline Veterinary dermatology & YES & YES & YES & NO & YES & YES & YES & YES & NA & NO \\
\hline
\end{tabular}

$\mathrm{YES}=$ has $\mathrm{MeSH}$ in record; $\mathrm{NO}=\mathrm{no} \mathrm{MeSH}$ in record; $\mathrm{NA}=$ title was not available in the catalogue

As discovered through the 040 Cataloguing Source tag in the MARC record, Queen's and Calgary also use Serials Solutions as the provider of cataloguing records for its package titles. Strangely, the search of their catalogues does not produce the same results with either Memorial or with each other. There is one title that is in the catalogues of both Memorial and Queen's that is not available in the Calgary catalogue. There is also one title for which Serials Solutions supplies a record containing MeSH to Memorial but there is no MeSH in the record for either Queen's or Calgary. In all cases where Memorial has no MeSH in its record, both Queen's and Calgary have MeSH. The remaining six libraries appear to catalogue all their titles locally, using copy from a variety of sources, predominately OCLC.

As can be seen from Table 13, copy with MeSH is actually available for all sixteen titles examined. For example, both McGill and McMaster have MeSH available for all titles but one. This one is a title for which Serials Solutions has provided MeSH to Memorial and which Dalhousie has catalogued. While some libraries may have added the title to their library catalogue before copy with $\mathrm{MeSH}$ became available in one of the major cataloguing utilities, there is no ready explanation as to why the libraries that apparently purchase records from the same source do not have the same availability of $\mathrm{MeSH}$ in their records. Anne Smithers (Head of Technical \& Document Services, Bracken Health Sciences Library. Personal Communication. October 15, 2007.) indicated that Queen's University has set their Serials Solutions profile to choose CONSER print records as their first priority and these are customized to serve as online records. Joyce Fahlman (Senior Cataloguer/Serials Team Resource Person. Personal Communication. October 15, 2007.) indicated that the University of Calgary set the CONSER neutral record as first priority in their Serials Solutions profile, while Memorial University of Newfoundland uses the CONSER online record as its first priority. This indicates that the different types of CONSER records available affect the ability of a library to secure MeSH on their journal records. This is an area requiring further examination.

\section{Conclusion}

While the use of MeSH is still much debated, the literature points to it being of value to searchers as an optimal search uses keywords that utilize the terminology most likely to be identified by the user. The variety of terms used to 
describe the one concept, the ineffectiveness of many of the words used in titles and chapters, and the ability of a controlled vocabulary to determine relevance point to the need for subject headings on records. Using specialized vocabulary familiar to its users, MeSH adds a degree of precision that more general vocabularies do not. Medical libraries should continue to use MeSH in this age of purchased record sets, and the majority of academic medical libraries in Canada still do. However, it is then incumbent upon the libraries to specify to vendors the need to include MeSH in the records when they are purchasing record sets. Academic medical libraries must work cooperatively within their university library systems to ensure that this need is not overlooked. Medical libraries must also take a lead role to improve the availability and consistency of cooperative cataloguing records, in ensuring that $\mathrm{MeSH}$ is added to full-level cataloguing records in cooperative databases such as OCLC, so that they are available to libraries, and also to vendors, for copy cataloguing. This is particularly true for monographs. Given the current policies that are in place, Canadian libraries in particular cannot depend on their national libraries to create records containing $\mathrm{MeSH}$. Without a concentrated effort by health libraries to ensure that $\mathrm{MeSH}$ is available on purchased record sets, either libraries will lose the benefits of MeSH or they will lose the benefits of cooperative cataloguing efforts. 
Partnership: the Canadian Journal of Library and Information Practice and Research, vol. 2, no. 2 (2007)

\section{Apppendix A: Acronyms Used}

$\begin{array}{ll}\text { AFMC } & \text { Association of Faculties of Medicine of Canada } \\ \text { CISTI } & \text { Canada Institute for Scientific and Technical Information } \\ \text { CONSER } & \text { Cooperative Online Serials } \\ \text { CRKN } & \text { Canadian Research Knowledge Network } \\ \text { LAC } & \text { Library and Archives Canada } \\ \text { LC } & \text { Library of Congress } \\ \text { LCSH } & \text { Library of Congress Subject Headings } \\ \text { MARC } & \text { machine readable cataloguing } \\ \text { MeSH } & \text { Medical Subject Headings } \\ \text { NLM } & \text { National Library of Medicine } \\ \text { PCC } & \text { Program for Cooperative Cataloging } \\ \text { RVM } & \text { Répertoire de Vedettes-Matière }\end{array}$


Partnership: the Canadian Journal of Library and Information Practice and Research, vol. 2, no. 2 (2007)

\section{Works Cited:}

Banerjee, Kyle. "Taking Advantage of Outsourcing Options: Using Purchased Records Sets to Maximize Cataloguing Effectiveness." Cataloguing and Classification Quarterly 32.1 (2001): 55-64.

Banush, David, Martin Kurth, and Jean Pajerek. "Rehabilitating Killer Serials." Library Resources \& Technical Services 49.3 (2005):190-203.

Bates, Marcia J. "Rethinking Subject Cataloging in the Online Environment." Library Resources \& Technical Services 33.4 (1989): 400-412.

Beheshti, Jamshid, Andrew Large, Pat Riva. "Cost savings to Canadian university and large urban public libraries from their use of National Library of Canada MARC records." Library Resources \& Technical Services 47.2 (2003): 44-57.

Bland, Robert N., Timothy Carstens, and Mark A. Stoffan. "Automation of Aggregator Title Access with MARC Processing." Serials Review 28.2 (2002): 108-112.

Brisson, Roger. "Vendor-supplied LC-MARC bibliographic records for German language assessment: An update and critical assessment." German Studies Library Group Newsletter 36/37 (2005): 11-24.

Byrum, John D. Jr. and David W. Williamson. "Enriching Traditional Cataloguing for Improved Access to Information: Library of Congress Tables of Contents Projects." Information Technology \& Libraries 25.1 (2006): 4-11. 
Carlyle, Allyson. "Matching LCSH and User Vocabulary in the Library Catalog." Cataloging \& Classification Quarterly 10.1/2 (1989): 37-64.

Carstens, Timothy and Heidi Buchanan. "The Future of the Catalog: A User-Friendly Academic Search Engine." Technical Services Quarterly 22.2 (2004): 37-47.

Cimino, J.J. "Desiderata for Controlled Medical Vocabularies in the $21^{\text {st }}$ Century." Methods of Information in Medicine 37.4/5 (1998): 394-403.

Denda, Kayo. "Beyond Subject Headings: A Structured Information Retrieval Tool for Interdisciplinary Fields." Library Resources \& Technical Services 49.4 (2005): 266275.

Derry, Sheena, Yoon Kong Loke, and Jeffrey K. Aronson. "Incomplete evidence: the inadequacy of databases in tracing published adverse drug reactions in clinical trials." BMC Medical Research Methodology 1:7 (2001). 13 April 2007. $<$ http://www.biomedcentral.com/1471-2288/1/7> .

Dijkers, MPJM. "Searching the literature for information on traumatic spinal cord injury: the usefulness of abstracts." Spinal Cord 41 (2003): 76-84.

Gault, Lora V., Mary Shultz and Kathy J. Davies. "Variations in Medical Subject Headings (MeSH) Mapping: From the Natural Language of Patron Terms to the Controlled Vocabulary of Mapped Lists." Journal of the Medical Library Association 90.2 (2002): 173-180. 
Gerhan, David R. "LCSH in vivo: Subject Searching Performance and Strategy in the OPAC Era." Journal of Academic Librarianship 15.2 (1989): 83-89.

Gorman, Michael. "Authority Control in the Context of Bibliographic Control in the Electronic Environment." Cataloguing \& Classification Quarterly 38.3/4 (2004): 1122.

Gross, Tina and Arlene G. Taylor. "What Have We Got to Lose? The Effect of Controlled Vocabulary on Keyword Searching Results." College \& Research Libraries 66.3 (2005): 212-230.

Jenuwine, Elizabeth S. and Judith A. Floyd. "Comparison of Medical Subject Headings and Text-Word Searches in MEDLINE to Retrieve Studies on Sleep in Healthy Individuals." Journal of the Medical Library Association 92.3 (2004): 349-353.

Jiang, Yumin, Jeanne A. Baker, and Lynda S. Kresge. "Toward Better Access to FullText Aggregator Collections." Serials Librarian 38.3/4 (2000): 291-297.

Khurshid, Zahiruddin. "Analytical Cataloging of Full-Text Journal Databases at a Middle East University." Cataloging \& Classification Quarterly 32.2 (2001): 81-89.

Kreider, Louisa J. "LCSH Works!: Subject Searching Effectiveness at the Cleveland Public Library and the Growth of Library of Congress Subject Headings Through Cooperation." Cataloging \& Classification Quarterly 29.1/2 (2000): 127-134. 
Partnership: the Canadian Journal of Library and Information Practice and Research, vol. 2, no. 2 (2007)

Leathem,Cecila. "Choices in Cataloguing Electronic Journals." Acquisitions Librarian 17.33/34 (2005): 73-83.

Libby, Katherine A. and Dana M. Caudle. "A Survey on the Outsourcing of Cataloguing in Academic Libraries." College \& Research Libraries 58.5 (1997): 550-560.

Lipscomb, Carolyn E. "Historical Notes: Medical Subject Headings (MeSH)." Bulletin of the Medical Library Association 88.3 (2000): 265-266.

Machado, Connie. K. “Just MeSHing Around! MeSH and LCSH in Rowland Medical Library's Catalog." Mississippi Libraries 67.4 (2003): 116-19.

Mann, Thomas. "Why LC Subject Headings are More Important Than Ever." American Libraries 34.9 (2003): 52-54.

Marner, J C. "Measuring the Success of Keyword Search Strategy in an Online Catalog." Technical Services Quarterly 11.2 (1993): 1-12.

Marshall, Julia. "Controlled Vocabularies: A Primer." Key Words 13.4 (2005): 120-124.

Martin, Charity K. and Elna L. Saxton. "Do We Catalog These or Not? How Research Libraries are Providing Bibliographic Access to Electronic Journals." Serials Librarian 40.3/4 (2001): 355-360.

McJunkin, Monica Cahill. "Precision and Recall in Title Keyword Searches." Information Technology \& Libraries 14.3 (1995): 161-171. 
McGregor, Bruce. "Medical Indexing Outside the National Library of Medicine." Journal of the Medical Library Association 90.3 (2002): 339-341.

McNutt, Eleanor M. and Ursula H. Poland. "Three-Way Catalog Division Combined with Conversion to Medical Subject Headings (MESH) in a Medium-Sized Medical Library." Bulletin of the Medical Library Association 62.4 (1974): 388-396.

Murphy, Linda S., Sibylle Reinsch, Wadie I. Najm, Vivian M. Dickerson, Michael A. Seffinger, Alan Adams, and Shiraz I. Mishra. "Searching Biomedical Databases on Complementary Medicine: the Use of Controlled Vocabulary Among Authors, Indexers, and Investigators." BMC Complementary and Alternative Medicine 3.3 (2003). 13 April 2007. <http://www.biomedcentral.com/1472-6882/3/3>.

Olson, Tony and Gary Strawn. "Mapping the LCSH and MESH Systems." Information Technology and Libraries 16.1 (1997): 5-19.

Riemer, John, Jina Choi Wakimoto, and Pat French. "Taming the Aggregators: Providing Access to Journals in Aggregator Databases." Serials Librarian 42.3/4 (2002): 157163.

Roe, Sandra K. "Subject Access Vocabularies in a Multi-Type Library Consortium." Cataloging \& Classification Quarterly 33.2 (2001): 55-67.

Schroeder, Penny. "Aggravating or Aggregating-Providing Access to Contents of Aggregator Databases: Highlights of the ALCTS Heads of Technical Services of 
Partnership: the Canadian Journal of Library and Information Practice and Research, vol. 2, no. 2 (2007)

Medium-Sized Academic Libraries Discussion Group." Library Collections, Acquisitions, and Technical Services 24 (2000): 336-339.

Shoham, Snunith and Rochelle Kedar. "The Subject Cataloguing of Monographs with the Use of Keywords." Cataloging \& Classification Quarterly 33.2 (2001): 29-54.

Sievert, MaryEllen Cullinan, Timothy B. Patrick, and John C. Reid. "Need a Bloody Nose Be a Nosebleed? Or, Lexical Variants Cause Surprising Results." Bulletin of the Medical Library Association 89.1 (2001): 68-71.

Smith, Marilyn J. and Pauline Atherton Cochrane. "Creating Better Subject Access with Multiple Vocabularies: Upgrading the Subject Heading List for the Alzheimer's Association." Library Resources \& Technical Services 43.1 (1999): 53-58.

Voorbij, Henk J. "Title keywords and subject descriptors: A comparison of subject search entries of books in the humanities and social sciences." Journal of Documentation 54.4 (1998): 466-476.

Wakimoto, Jina Choi. "Utilization of a Set of Vendor-Supplied MARC Records to Provide Access to Journals in an Aggregator Database." Serials Librarian 43.1 (2002): 7995.

Wasylenko, Lydia W. "Optimizing End-User Access to Aggregations of Full-Text EJournals: Highlights of the ALCTS CCS Catalog Management Discussion Group Program." Library Collections, Acquisitions, and Technical Services 23.3 (1999): $372-4$ 
Partnership: the Canadian Journal of Library and Information Practice and Research, vol. 2, no. 2 (2007)

Womack, Kristina R. "Conformity for Conformity's Sake? The Choice of a Classification System and a Subject Heading System in Academic Health Sciences Libraries." Cataloging \& Classification Quarterly 42.1 (2006): 93-115.

Yee, Martha M. "New Perspectives on the Shared Cataloging Environment and a MARC 21 Shopping List." Library Resources \& Technical Services 48.3 (2004): 165-178.

Young, Naomi Kietzke. "The Aggregator-Neutral Record: New Procedures for Cataloging Continuing Resources." Serials Librarian 45.4 (2004): 37-42. 